\title{
Prevalence of goiter and iodine status among 6-12 years school age children in district Kohat, Pakistan
}

\author{
Fazli Subhan ${ }^{1}$, Muhammad Jahangir ${ }^{2}$, Saira Saira ${ }^{3}$, Rehman Mehmood Khattak ${ }^{4}$, Muhammad \\ Shahab ${ }^{5}$, Matiul Haq ${ }^{6}$, Muhammad Nasir Khan Khattak
}

${ }^{1}$ M.Phil student; ${ }^{2}$ M.Phil student; ${ }^{3}$ Lecturer; ${ }^{7}$ Assistant Professor and Head; Department of Zoology, Hazara University Mansehra, Pakistan. ${ }^{4}$ Lecturer, Department of Zoology, Kohat University of Science and Technology, Kohat, Pakistan. ${ }^{5}$ Professor, Department of Animal Sciences, Quaid-i-azam University, Islamabad, Pakistan. ${ }^{6}$ Senior Scientific Officer, Institute of Radiotherapy and Nuclear Medicine (IRNUM), Peshawar, Pakistan.

\begin{abstract}
Pakistan is considered to be one of the most severely iodine deficient countries in the region. A decade earlier, $70 \%$ of the population was estimated to be at risk of iodine deficiency. However, the recent use of iodized salt has reduced the intensity of the problem. Earlier studies regarding iodine deficiency in Pakistan were restricted to the northern mountainous regions, but have now been extended to the sub-Himalaya areas and the plains of Punjab. The aim of the present study was to investigate the prevalence of goiter and iodine status among school children in district Kohat, Pakistan. The 30 cluster approach was adopted for the study. From each cluster, 40 samples were collected from school going children. The palpation method was used to measure goiter grade, whereas, for urinary iodine estimation, the wet digestion method was used. The prevalence of goiter in the district was found to be $35 \%$ (37.16\% in boys and $33 \%$ in girls). The median urinary iodine concentration was found to be $56 \pm 31.19 \mu \mathrm{g} / \mathrm{L}$. Estimation of iodine content in salt illustrated that $56.8 \%$ people were consuming non-iodized salt and $43.5 \%$ were using iodized salt. The current study suggests a severe iodine deficiency in school children of district Kohat and regular iodine supplementation is required on an instant basis.
\end{abstract}

Keywords: Goiter, Iodine status, Urinary iodine concentration, School children, Pakistan.

\section{Introduction}

Iodine is an essential trace mineral used in the synthesis of thyroid hormones that are utilized by almost all the tissues of the body. Its deficiency leads to a number of disorders collectively termed as iodine deficiency disorders (IDDs). ${ }^{1,2}$ These include cretinism, hypothyroidism and brain damage etc. ${ }^{3}$ Iodine is added to the surface water of non coastal regions via rain, whereas ocean spray and rain both introduce iodine into coastal regions. ${ }^{4}$ The median urinary iodine concentration (UIC) in school age children is used to estimate the iodine status of general population. ${ }^{5}$

Globally, 111 countries have adequate iodine nutrition, 30 countries remain iodine-deficient, 9 are moderately deficient, 21 are mildly deficient, and none are currently considered severely iodine-deficient. Iodine nutrition has distinctly improved over the past 3 decades - an improvement of $<10 \%$ to $\approx 70 \%$ in terms of household access to iodized salt. ${ }^{6}$

According to a WHO report 1990, an estimated population of 50 million people were affected by iodine deficiency in Pakistan, while the prevalence of goiter ranged from $55 \%$ in the plain areas to as high as $80-90 \%$ in the mountainous ranges. ${ }^{7}$ However, the situation has been improved much in the last decade. Reports regarding the consumption of iodized salt have been positive and, as a result, the reduction in goiter rate is encouraging.

\section{Practice Points}

- Pakistan is considered to be one of the most severely iodine deficient countries in the region.

- We found that the overall goiter prevalence rate in district Kohat was 35\% (37\% in boys and $33 \%$ in girls)

- The overall median UIC was found to be $56 \pm 31.19 \mu \mathrm{g} / \mathrm{L}(56 \pm 31.04 \mu \mathrm{g} / \mathrm{L}$ in boys and $56 \pm 31.37 \mu \mathrm{g} / \mathrm{L}$ in girls).

- The overall iodized salt consumption by the population was found to be $43.5 \%$.

- Salt industries should produce and market quality iodized salt, and local administration and policy makers should tackle the problem by implementing effective programs and policies.

According to the National Nutrition Survey (NNS) 2011, the median urinary iodine concentration was $154 \mu \mathrm{g} / \mathrm{L}$ in 6-12 years children in Khyber Pakhtoonkhwa (KP), Pakistan. In KP, $74.2 \%$ of children are iodine sufficient, $18.9 \%$ are mildly iodine deficient and $5.8 \%$ are moderately iodine deficient, whereas only $1 \%$ children are severely iodine deficient. ${ }^{8}$ However, some studies still reporting higher

Correspondence: Dr. Muhammad Nasir Khan Khattak, Assisstant Professor, Department of Zoology, Hazara University Mansehra, Pakistan. Email: mnasir43663@gmail.com. 
a prevalence rate. A recent study in district Charsadda, Pakistan showed $10.9 \%$ goiter prevalence and median urinary iodine concentration to be $89.9 \mu \mathrm{g} / \mathrm{L}$ among school going children. ${ }^{9}$

District Kohat is located in the south of Peshawar district and lies between north latitude $32^{\circ} 47^{\prime}$ and $33^{\circ}$ $53^{\prime}$ and east longitude $70^{\circ} 34^{\prime}$ and $72^{\circ} 17^{\prime}$. River Indus is located to the east and district Karak is in the south, whereas Orakzai hills are located to the West. The total area of district Kohat is 2,973 square miles. ${ }^{10}$ District Kohat is an arid area and encompasses both the hilly and plain areas.

Iodine nutritional status is unexplored in district Kohat. Therefore the current study was undertaken to investigate the iodine nutrition status and goiter prevalence among the school going children in the district. The study provides baseline information regarding the mentioned objectives in the area which will help the policy makers in launching the iodine prophylaxis program at the national or sub-national level.

\section{Materials and Methods}

\section{Study design and sampling method}

For the purpose of the study, thirty clusters approach was adopted for the current study i.e. the district was divided into thirty clusters. In each cluster, 40 primary school (6-12 years) children were randomly selected. Equal number of male $(n=20)$ and female $(n=20)$ children were sampled for the study. A total of 1200 children were recruited for the study. A questionnaire was provided to each child for the purpose to get basic information about each recruited subject and their knowledge about iodized salt.

\section{Goiter grading}

Goiter size was graded (0, I, II) according to the WHO/ UNICEF/ICCIDD criteria ${ }^{11}$ through palpation method by single trained observer. The observer was trained at district headquarter hospital Kohat for a month.

- Grade 0: not visible, not palpable

- Grade I: palpable, not visible

- Grade II: palpable and visible

The sum of goiter grade I and grade II was taken as total goiter rate.

\section{Urinary iodine analysis}

Urine sample was collected from each student in a tight screw capped tubes and transferred to the Institute of Radiotherapy and Nuclear Medicine (IRNUM), Peshawar and was kept at $4^{\circ} \mathrm{C}$ for urinary iodine analysis. Iodine intake by a person can be investigated measuring urinary iodine concentration. The levels of iodine deficiency were defined according to $\mathrm{WHO} /$ UNICEF/ICCIDD criteria which are as follow ${ }^{12}$ :

Severe iodine deficiency $(<20 \mu \mathrm{g} / \mathrm{L})$
Moderate iodine deficiency $(20-49 \mu \mathrm{g} / \mathrm{L})$

Mild iodine deficiency $(50-99 \mu \mathrm{g} / \mathrm{L})$

- Optimal (100-199 $\mu \mathrm{g} / \mathrm{L})$

- Risk of iodine induced hyperthyroidism within 5-10 years following introduction of iodized salt in susceptible groups $(200-299 \mu \mathrm{g} / \mathrm{L})$

- Risk of adverse health consequences [iodine induced hyperthyroidism, autoimmune thyroid diseases] $(>300 \mu \mathrm{g} / \mathrm{L})$.

The urinary iodine concentration was measured by its catalytic action on the reduction of the Ceric ion $\left(\mathrm{Ce}^{+4}\right)$ to the Cerous ion $\left(\mathrm{Ce}^{+3}\right)$ coupled with the oxidation of $\mathrm{As}^{+3}$ to $\mathrm{As}^{+5}$, in the oxido-reduction reaction between ceric ammonium sulfate and arsenious acid. The mentioned reaction is called the Sandell-Kolthoff reaction, ${ }^{13,14}$ is as under:

$2 \mathrm{Ce}^{+4}+2 \mathrm{I}^{-} \rightarrow 2 \mathrm{Ce}^{+3}+\mathrm{I}_{2}$

$\mathrm{I}_{2}+\mathrm{As}^{+3} \rightarrow \mathrm{As}^{+5}+2 \mathrm{I}^{-}$

The reaction is slow, but can be accelerated by the iodide ion. The Cerous ion $\left(\mathrm{Ce}^{+3}\right)$ is colorless, whereas Ceric ion $\left(\mathrm{Ce}^{+4}\right)$ has a yellow color. Thus, the route of the reaction can be followed by the vanishing of the yellow color as the Ceric ion is reduced into Cerous ion. The speed of this color disappearance is directly proportional to the amount of iodide catalyzing it and is read by a spectrophotometer, after an exact time, at 405 nm. $^{13,14}$

\section{Salt samples analysis}

A total of 108 samples of house hold salt were collected from the district and iodine was estimated using spot testing kit. The kit is manufactured by Nutrition division of National Institute of Health (NIH), Islamabad, Pakistan. The kit tests enrichment of salt with potassium iodate. Each sample was tested three times and the consistent results were considered for the study. By putting a drop on salt sample, the color obtained was compared with the colors on standard scale provided with the Kits $(0 \mathrm{ppm}, 15 \mathrm{ppm}, 25 \mathrm{ppm}, 50 \mathrm{ppm}$, and $75 \mathrm{ppm}$ ) to evaluate the concentration of iodine in the salt.

\section{Ethical consent}

A written permission was taken from district education officer of Kohat, Pakistan.

\section{Data analysis}

Data were analyzed age and sex wise for goiter and urinary iodine concentration using MS excel 2007.

\section{Results}

\section{Goiter prevalence}

The results of the current study show the total goiter rate to be $35 \%$ in the district. In boys the goiter prevalence was found to be higher (37\%) than girls (33\%) (Table $1)$. The data were analyzed age wise in both genders 
separately. Among boys the highest prevalence (57\%) was recorded in 12 years of age, followed by 11 years $(47 \%), 9$ years $(39 \%), 10$ years $(33 \%), 8$ years $(33 \%), 7$ years $(30 \%)$ and 6 years $(29 \%)$. Among girls of 12 years the highest goiter prevalence $(73 \%)$ was recorded, followed by 11 years $(42 \%), 10$ years $(41 \%), 9$ years $(40 \%), 8$ years $(31 \%), 7$ years $(29 \%)$ and 6 years (29\%) (Table 1).

\section{Urinary iodine concentration}

For urinary iodine analysis, 1170 samples were collected from school going children of age 6-12 years. The overall median UIC was found to be $56 \pm 31.19 \mu \mathrm{g} / \mathrm{L}$ showing mild iodine deficiency. In boys the median UIC was found to be $56 \pm 31.04 \mu \mathrm{g} / \mathrm{L}$ and in girls it was $56 \pm 31.37 \mu \mathrm{g} / \mathrm{L}$. Overall $8 \%$ were severely iodine deficient, $30 \%$ were moderately iodine deficiency, $54.70 \%$ had mild urinary iodine and only $7.69 \%$ children had iodine intake more than recommended level. The maximum median UIC $(63 \mu \mathrm{g} / \mathrm{L})$ was noticed for the children of 9 and 12 years whereas minimum median UIC $(55 \mu \mathrm{g} / \mathrm{L})$ was found in the children of 6 years (Table 2).

\section{Iodine contents of salt samples}

A total of 108 samples were tested for iodine contents. The analysis showed that $61 / 108(56.48 \%)$ samples of Kohat district were non-iodized, 19/108 (17.59\%) salt samples had iodine contents of $15 \mathrm{ppm}, 2 / 108(1.85 \%)$ salt samples had $25 \mathrm{ppm}$ iodine, 11/108 (10.18\%) salt samples had $50 \mathrm{ppm}$ whereas $15 / 108(13.88 \%)$ salt samples had $\geq 75$ ppm iodine contents (Figure 1).

Table 1: Age and gender wise prevalence of goiter among school going children $(n=1200)$

\begin{tabular}{|l|c|c|c|c|c|}
\hline \multirow{2}{*}{ Age (years) } & \multicolumn{2}{|c|}{ Goiter Grade 0 } & \multicolumn{2}{c|}{ Goiter Grade I } & \multirow{2}{*}{$\begin{array}{c}\text { Total Goiter } \\
\text { Rate } \\
\text { n (\%) }\end{array}$} \\
\cline { 2 - 5 } & $\begin{array}{c}\text { Boys } \\
\mathbf{n}(\mathbf{\%})\end{array}$ & $\begin{array}{c}\text { Girls } \\
\mathbf{n}(\mathbf{\%})\end{array}$ & $\begin{array}{c}\text { Boys } \\
\mathbf{n}(\mathbf{\%})\end{array}$ & $\begin{array}{c}\text { Girls } \\
\mathbf{n}(\mathbf{\%})\end{array}$ & $47(23.38 \%)$ \\
\hline 6 years & $52(71.23 \%)$ & $91(71.09 \%)$ & $21(28.76 \%)$ & $37(28.9 \%)$ & $47 \%)$ \\
\hline 7 years & $50(70.42 \%)$ & $96(70.58 \%)$ & $21(29.57 \%)$ & $40(29.41 \%)$ & $61(29.46 \%)$ \\
\hline 8 years & $64(67.36 \%)$ & $66(69.47 \%)$ & $31(32.63 \%)$ & $29(30.52 \%)$ & $60(31.57 \%)$ \\
\hline 9 years & $61(61 \%)$ & $63(60 \%)$ & $39(39 \%)$ & $42(40 \%)$ & $81(39.51 \%)$ \\
\hline 10 years & $77(66.95 \%)$ & $45(59.21 \%)$ & $38(33.04 \%)$ & $31(40.78 \%)$ & $69(36.12 \%)$ \\
\hline 11 years & $53(53.53 \%)$ & $26(57.77 \%)$ & $46(46.46 \%)$ & $19(42.22 \%)$ & $65(45.13 \%)$ \\
\hline 12 years & $20(42.55 \%)$ & $4(26.66 \%)$ & $27(57.44 \%)$ & $11(73.33 \%)$ & $38(61.29 \%)$ \\
\hline Total & $377(62.83 \%)$ & $402(67 \%)$ & $223(37.16 \%)$ & $198(33 \%)$ & $421(35.08 \%)$ \\
\hline
\end{tabular}

Table 2: Age and gender wise median urinary iodine concentration of school going children

\begin{tabular}{|c|c|c|c|c|c|c|c|}
\hline Age & $\begin{array}{c}<\mathbf{2 0} \boldsymbol{\mu g} / \mathbf{L} \\
\mathbf{n}(\mathbf{\%})\end{array}$ & $\begin{array}{c}\mathbf{2 0 - 4 9} \boldsymbol{\mu g} / \mathbf{L} \\
\mathbf{n}(\%)\end{array}$ & $\begin{array}{c}\mathbf{5 0 - 9 9} \boldsymbol{\mu g} / \mathbf{L} \\
\mathbf{n}(\%)\end{array}$ & $\begin{array}{c}\mathbf{1 0 0 - 1 9 9} \boldsymbol{\mu g} / \mathbf{L} \\
\mathbf{n}(\%)\end{array}$ & $\begin{array}{c}\mathbf{2 0 0}-299 \\
\boldsymbol{\mu g} / \mathbf{L} \mathbf{n}(\%)\end{array}$ & $\begin{array}{c}\mathbf{3 0 0} \boldsymbol{\mu g} / \mathbf{L} \\
\mathbf{n}(\%)\end{array}$ & $\begin{array}{c}\text { UIC } \mathbf{~ m e}- \\
\mathbf{d i a n} \boldsymbol{\mu g} / \mathbf{L}\end{array}$ \\
\hline 6 years & $17(6.88 \%)$ & $76(30.36 \%)$ & $138(55.87 \%)$ & $16(6.47 \%)$ & 0 & 0 & 55 \\
\hline 7 years & $28(10.98 \%)$ & $69(27.05 \%)$ & $144(56.47 \%)$ & $14(5.49 \%)$ & 0 & 0 & 56 \\
\hline 8 years & $8(4.25 \%)$ & $60(31.91 \%)$ & $100(23.19 \%)$ & $20(10.63 \%)$ & 0 & 0 & 56 \\
\hline 9 years & $15(7.32 \%)$ & $59(28.78 \%)$ & $113(55.12 \%)$ & $16(7.80 \%)$ & $2(0.97 \%)$ & 0 & 63 \\
\hline 10 years & $9(5.92 \%)$ & $53(34.86 \%)$ & $80(52.63 \%)$ & $10(6.57 \%)$ & 0 & 0 & 56 \\
\hline 11 years & $8(9.09 \%)$ & $27(30.68 \%)$ & $45(51.13 \%)$ & $08(9.09 \%)$ & 0 & 0 & 56 \\
\hline 12 years & $4(11.42 \%)$ & $7(20 \%)$ & $20(57.14 \%)$ & $4(11.42 \%)$ & 0 & 0 & 63 \\
\hline Total & $89(8.11 \%)$ & $351(29.91 \%)$ & $640(54.70 \%)$ & $88(7.52 \%)$ & $2(0.17 \%)$ & 0 & 56 \\
\hline
\end{tabular}

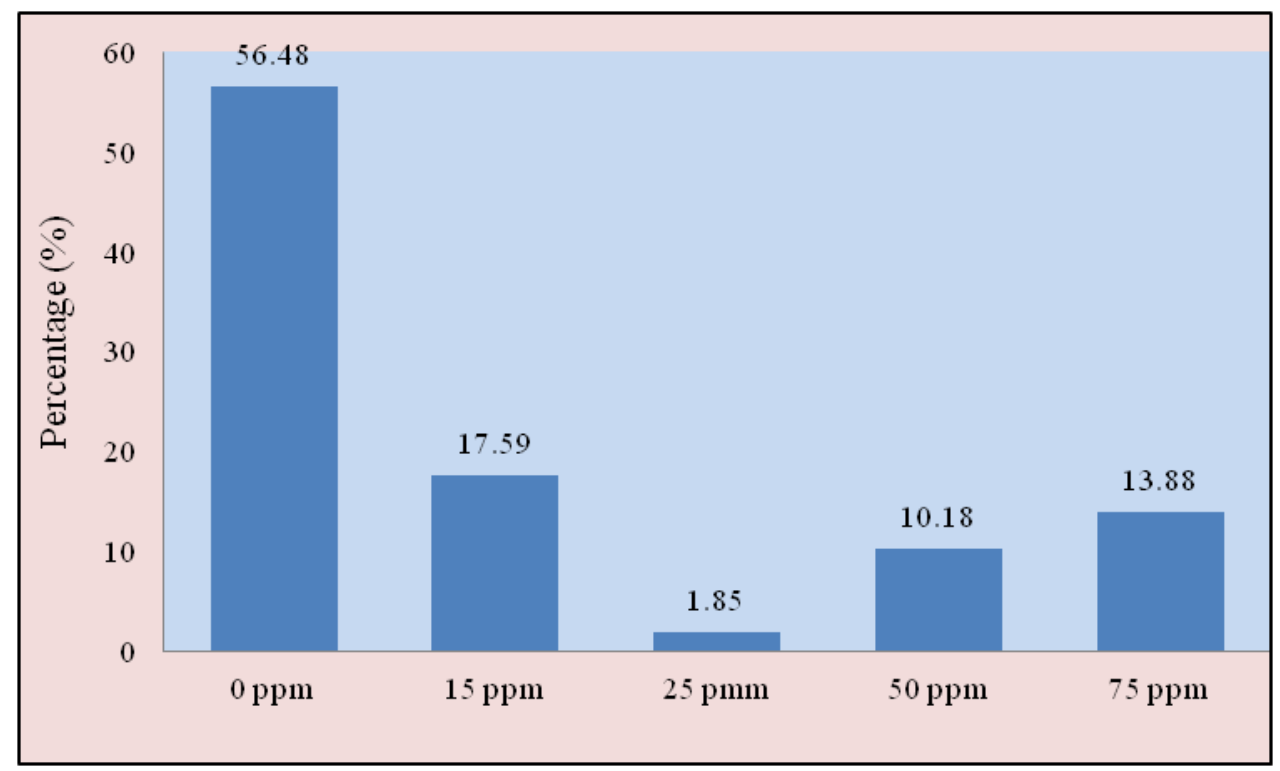

Figure 1: Iodine concentration in household's cooking salt samples of the district Kohat 


\section{Discussion}

Iodine deficiency leads to many disorders which are collectively known as iodine deficiency disorders (IDDs). ${ }^{15}$ To assess the iodine deficiency disorders in a region, school children of age 6-12 years are considered as satisfactory markers. Children are true representatives of community and are sampled to investigate the iodine status in general population via evaluation of urinary iodine concentration. ${ }^{12,16}$

In Pakistan goiter prevalence has been studied in different regions. In the capital city of Islamabad and its surroundings the reported goiter prevalence ranges from $40-72 \%$ in school going children. ${ }^{17}$ District Swat of Pakistan was severely endemic to goiter, with $45 \%$ prevalence in girls and $52 \%$ prevalence in boys. ${ }^{18}$ Similar study was conducted in a part of district Karak, where total goiter rate was found to be $47.55 \%$ (49.77\% in males and $40.58 \%$ in females). ${ }^{19} \mathrm{~A}$ recent study at district Charsadda reported the total goiter rate to be $10.9 \%$ (11.5\% in females and $10.2 \%$ in males $).{ }^{9}$

The published studies regarding goiter prevalence in Charsadda and Peshawar showed lower values than our results. ${ }^{9,20}$ Other studies reveal higher values than our findings, which are due to less consumption of iodized salt and mountainous topography. ${ }^{17,20,21}$ The recent data from district Karak provided considerably lower values for goiter prevalence than our results. ${ }^{22} \mathrm{~A}$ relevant study conducted in Romania reported lower goiter rate among school age children which is $30 \%{ }^{23}$ Similarly the study conducted in Isfahan, Iran recorded prevalence of goiter is $32.9 \%$ which is less than our study. ${ }^{24}$ The recorded data regarding goiter prevalence among school of Eastern Nepal is also less than our findings. ${ }^{25}$ The median urinary iodine concentration values reported by Saira et al. ${ }^{9}$ are higher than our findings. Higher values were also reported in school age children of district Karak by other studies. ${ }^{19,22}$ Similarly, findings of Isfahan and Eastern Nepal study depict higher values of urinary iodine concentration $^{24,25}$

The results of salt samples analyzed for iodine contents reveals higher values than recently reported results from district Charsadda of KPK, where 30\% of population was consuming iodized salt. ${ }^{9}$ Comparatively, in district Kohat, $43.5 \%$ population is using iodized salt. In the district Karak, located adjacent to Kohat, $72.3 \%$ population is consuming non-iodized salt. ${ }^{22}$ Most of the people were unaware of iodized salt and iodine deficiency disorders. Another study conducted in 1999 in district Abbottabad reported that $58.8 \%$ population was consuming iodized salt showing comparatively higher use of iodized salt. ${ }^{26}$

\section{Conclusion}

District Kohat is endemic to goiter with mild iodine deficiency. We found that the overall goiter prevalence rate in district Kohat was 35\% (37\% in boys and 33\% in girls). The overall iodized salt consumption by the population was found to be $43.5 \%$. The main reason for this public health problem includes: Lack of awareness of people about iodine deficiency and its complications, consumption of non-iodized salt, lack of effective education programs by district administration and policy makers. Immediate prophylaxis program is needed for correction of the problem in the region.

\section{References}

1. Maberly GF. Iodine deficiency disorders: contemporary scientific issues. J Nutr 1994;322 (8):1473-8.

2. Delange $\mathrm{F}$. The disorders induced by iodine deficiency. Thyroid 1994;4(1):107-28.

3. Hazarika NC, Mahanta J. Environmental iodine deficiency and goiter prevalence in a block area of the north eastern region: a retrospective analysis. J Hum Ecol 2004;15(2):113-7.

4. Bichsel Y, von Gunten U. Oxidation of iodine and hypo-iodous acid in the disinfection of natural waters. Environ Sci Technol 1999;33:4040-5.

5. WHO/UNICEF/ICCIDD. Assessment of iodine deficiency disorders and monitoring their elimination. A guide for programme managers. Geneva: World Health Organization, 2007.

6. Pearce EN, Andersson M, Zimmermann MB. Global iodine nutrition: where do we stand in 2013? Thyroid 2013;23(5):523-8.

7. WHO. Report to the 43rd World Health Assembly. Geneva: World Health Organization, 1990.

8. Planning Commission. National Nutrition Survey Report. Islamabad: Planning Commission, Planning and Development Division, Government of Pakistan, 2011.

9. Saira S, Khattak RM, Khan AA, Rehman A, Khattak MNK. Prevalence of goiter and assessment of iodine status in 6-12 years school children and pregnant women of district Charsadda, Pakistan. Acta Endocrinologica (BUC) 2014;10(1):65-75.

10. Khyber.org. General Description \& Geography of Kohat District: Extracts from the Gazetteer of Kohat District. http://www.khyber.org/ publications/036-040/generaldesc.shtml (accessed 31 Dec 2014).

11. WHO/UNICEF/ICCIDD. Indicators for assessing iodine deficiency disorders and their control through salt iodination. Geneva: World Health Organization, 1994.

12. WHO. Assessment of the iodine deficiency disorders and monitoring their elimination. Geneva: World Health Organization, 2001.

13. Adam M, Giellen J, Gognard T, Bourguignon J, 
Rigo J, Zolde J, et al. Method for measuring the urinary iodine concentration - diagnostic criteria of iodine deficiency (in Romanian). Clujul Medical 1996;69(4):492-6.

14. Dunn JT, Crutchfield HE, Gutekunst R. Methods for measuring iodine in urine. Wageningen: International Council for Control of Iodine Deficiency Disorders, 1993.

15. Hetzel BS. The iodine deficiency disorders (IDD) and their eradication. Lancet 1983;322 (8359):1126-9.

16. ICCIDD/UNICEF/WHO. Indicators for assessing iodine deficiency disorders and their control programs. Report of a joint ICCIDD/ WHO/UNICEF Consultation,3-5, November 1992. Geneva: World Health Organization, 1993.

17. Ali TZ, Anis RA, Shami SA, Ijlal F, Aqeer FIF. Prevalence of Goiter in School-going Children in a Union Council near Islamabad. Pak J Med Research 2007;46(4).

18. Akhtar A, Ullah Z. Goiter in district Swat, NWFP-Pakistan: Current situation. Pakistan $J$ Med Res 2003;42(2):74-6.

19. Khattak MNK, Haq M, Khan A, Cheema A. Prevalence of endemic goiter and urinary iodine contents in the population of Lawaghar and Chontra areas of district Karak (North Western Frontier Province), Pakistan. Pak J Sci Res 2006;58(1-2):1-4.
20. Ullah Z, Akhtar T, Khan AU, Nawab G, Mati-ul-Haq. Goitre in school children versus use of iodized salt in Peshawar. Pak J Med Research 2000;40(3):90-4.

21. Godwin P, Moti-ur-Rehman-Khan M, Anis RA, Sughra F. Report of a qualitative survey of people's perception of IDD in a village of Hazara Division. Islamabad: National Institute of Health, Government of Pakistan, 1989.

22. Jahangir M Khattak RM, Shahab M, Tauseef I, Khattak MNK. Prevalence of goiter and iodine nutritional status in school age children of district Karak, Khyber Pakhtunkhwa, Pakistan. Acta Endocrinologica (BUC) 2015. (In press)

23. Simescu M. Stuy on the evolution of endemic goiter in Romania. Endocrinologie 1991;29(12):73-83.

24. Siavash M, Keshteli AH, Hashemipour M, Amini M. Increased goiter prevalence in school children of Isfahan despite long-term iodine sufficiency. Hormone 2009; 8(1):47-51.

25. Gelal B, Chaudari RK, Nepal AK, Sah GS, Lamsal M, Brodie DA. Baral N. Iodine deficiency disorders among primary school children in Eastren Nepal. Indian $J$ Pediatr 2011;78:45-8.

26. Iqbal N, Haq M, Khan SM, Shah SA, Bano S. Assessment of iodine deficiency in school going children in Abbottabad-Pakistan. Pak $J$ Med Sci 1999;15(4):325-9. 